\title{
The Contamination Effects and Toxicological Characterization of $o$-Chlorobenzylidene Manolonitrile
}

\author{
VIOREL GHEORGHE ${ }^{1}$, CATALINA GABRIELA GHEORGHE ${ }^{1 *}$, ANDREEA BONDAREV $^{1}$, \\ CONSTANTIN NICOLAE TOADER ${ }^{2}$, MIHAELA BOMBOS ${ }^{3}$, MATEI VASILE ${ }^{1}$ \\ ${ }^{1}$ Petroleum - Gas University of Ploiesti, 39 Bucuresti Blvd., 100520, Ploiesti, Romania \\ ${ }^{2}$ Centrul de Cercetare Stiintifica pentru Aparare CBRN si Ecologie., 225 Oltenitei, 041309, Bucharest, Romania \\ ${ }^{3}$ National Institute for Research Development for Chemistry and Petrochemistry- ICECHIM-Bucuresti, 202 Splaiul \\ Independetei, 060021, Bucharest, Romania
}

\begin{abstract}
Toxicological characterization and global assessment of the toxicity of some chemicals used in the specific technique of the defense and public order system (e.g. o-chlorobenzylidene manolonitrile which enters the composition of the CS gas) is especially useful for environmental protection. Based on the results obtained, the toxicological characterization (acute lethal toxicity) and the harmful potential of some toxic substances, individual or in mixture, against euythermal sweet fish are established. The tests performed aim to change the behavior of the species studied in the presence of chlorobenzylidene manolonitrile, a substance used in the technique of defense and public order system. The tests established the toxicity values of acute lethal concentration LC50 and serve to further determine the maximum allowable concentration that inhibits the development of normal fish fauna in contaminated waters. The test results allow the toxicological characterization and measurement of the acute lethal toxicity of an inhibitor, in order to make more efficient its elimination from the contaminated environment.
\end{abstract}

Keywords: o-chlorobenzylidene malononitrile, water pollutant, medium lethal concentration, LC 50

\section{Introduction}

The widespread use of such toxic substances dates back to World War I. There are indications that such practices were used before its outbreak. At the international level, several conventions have been signed banning the use of chemicals in case of war. The most important of these conventions was signed in Paris in 1993, under the Convention on the Prohibition of the Development, Production, Stockpiling and Use of Chemical Weapons and on Their Destruction, which is better known as the Chemical Weapons Convention.

War toxins can be classified into two main groups, lethal ones such as neurotoxics and cyanide derivatives, vesicants and suffocants and non-lethal ones, which are chemicals that cause temporary physical or mental disability and include irritants (e.g. tear gas, fumigant).

Riot control agents, such as CS, are considered chemical weapons if used as a method of warfare. CS is among the most widely used and known riot control agent. CS gas is generally accepted as being non-lethal. It was first synthesized by two Americans, Ben Corson and Roger Stoughton, at Middlebury College in 1928 [1].

The defining component of the CS gas is a cyanocarbon, with chemical formula $\mathrm{C}_{10} \mathrm{H}_{5} \mathrm{ClN}_{2}$, whose structure is shown in Figure 1 and whose synthetic preparation is shown in Figure 2.<smiles>N#CC(C#N)=Cc1ccccc1Cl</smiles>

Figure 1. Molecular structure of $o$-chlorobenzylidene manolonitrile [13]

*email: ghe.catalina@yahoo.com 
Thus, CS is synthesized by the reaction of 2-chlorobenzaldehyde and malononitrile via the Knoevenagel condensation. The reaction is catalysed with a weak base, like piperidine or pyridine.

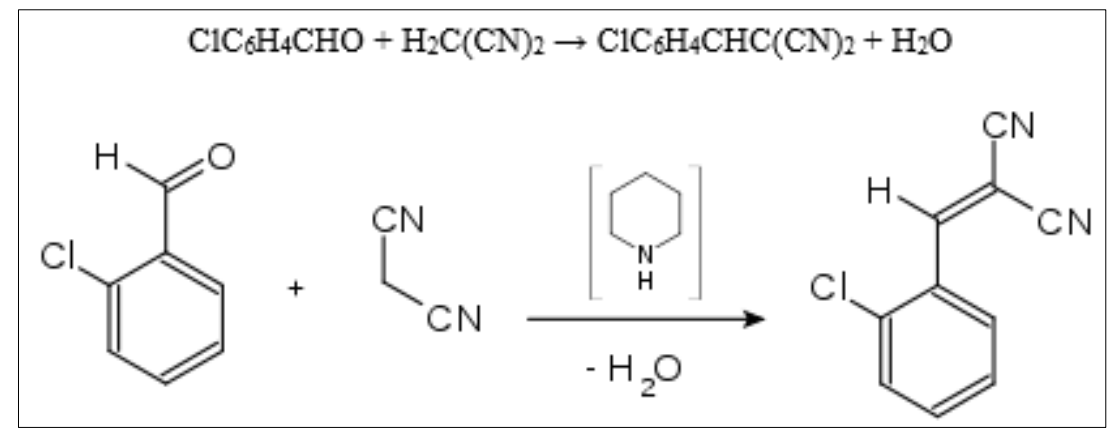

Figure 2. Knoevenagel condensation

The use of CS in war is prohibited under the terms of the Chemical Weapons Convention. Chemical Weapons Convention prohibits only military use. A common conception of a chemical weapon (CW) is of a toxic chemical contained in a delivery system such as a bomb or artillery shell. While technically correct, a definition based on this conception would only cover a small portion of the range of things the Chemical Weapons Convention (CWC) prohibits as 'chemical weapons' [2].

According to Organisation for Prohibition of Chemical Weapons (OPCW), states can legitimately possess riot control agents and use them for domestic law enforcement purposes, but states that are members of the Chemical Weapons Convention must declare what type of riot agents they possess.

CS is used in spray form by many police forces as a temporary incapacitant for persons who are violently aggressive.

The CS reacts with moisture on the skin and in the eyes, causing a burning sensation and the immediate forceful and uncontrollable shutting of the eyes. Effects usually include tears streaming from the eyes, profuse coughing, exceptional nasal discharge that is full of mucus, burning in the eyes, eyelids, nose and throat areas, disorientation, dizziness and restricted breathing. It will also burn the skin where sweaty or sunburned. In highly concentrated doses, it can also induce severe coughing and vomiting. Most of the immediate effects wear off within an hour (such as exceptional nasal discharge and profuse coughing), although respiratory and oral symptoms may persist for months [3].

Although described as a non-lethal weapon for crowd control, studies have raised doubts about this classification. CS can cause severe pulmonary damage and can also significantly damage the heart and liver [4].

Recently in our country large quantities of CS was used by the The Gendarmerie of Bucharest against civilians during the protests of 10 August 2018 in Bucharest [5].

Abroad one of the most recent and well - known use of CS was in Hong Kong (China) where from June 12 to August 4, 2019, police used 1000 tear gas canisters. Then, on the single day of August 5, police fired more than 800 tear gas canisters in their operations throughout almost every district of the city [6].

In one instance, a tear gas canister was deployed indoors, in Kwai Fong Station during a march, on August 11, 2019. The police initially denied the incident [7].

The immediate effects of CS Gas on humans occur at low concentrations and cause irritating action on the skin and mucous membranes. The first target organs are the eyes: intense tearing due to irritation of the mucous membrane of the eye membrane, blepharospasm, conjunctivitis, periorbital edema, burning and pain [8].

Assessment of the acute toxic potential of this chemical is necessary to determine the adverse health effects that may occur as a result of accidental or deliberate short-term exposure.

Acute toxicity is the effect of intense, short-term exposure of organisms to the action of the toxic compound. The usual duration of acute exposure is generally 96 hours (Sprague, 1969) or shorter [9]. 
The REACH Regulation defines, for example, acute oral toxicity by adverse effects occurring after the oral administration of one or more doses of the substance within $24 \mathrm{~h} \mathrm{[10].} \mathrm{Investigated} \mathrm{problems} \mathrm{may}$ be clinical signs of toxicity, abnormal changes of body weight and / or pathological changes of organs and tissues, which in some cases can cause death (according to SR 13216/1994) [11].

Thus, the effects of toxins can be quantified (eg LD50 / LC50 - lethal dose / lethal concentration that induces the death of $50 \%$ of tested individuals). The scale for quantifying the effects is also applied in the case of the irritating or sensitizing effect, this being classified as weak, moderate, strong or severe, depending on the values. In the case of toxics from aqueous solutions, the test results allow the global evaluation of the toxicity of the analyzed impurity. Thus, LC50 represents the average lethal concentration of a contaminant in solution that is lethal to $50 \%$ of the test aquatic organisms at continuous exposure over a set period of time.

In this paper, the toxicity of o-chlorobenzylidene manolonitrile, the substance used in the specific technique of the defense and public order system, on the Barbus Capoeta Tetrazone fish, was studied by abnormal changes in body weight and changes in abnormal motor behavior.

\section{Material and methods}

Experimental studies were performed in accordance with SR 13216/1994-. Tests with aquatic organisms. Determination of acute lethal toxicity of impurities and wastewater against freshwater fish (eurytherms) [12].

Acute toxicity is the visible adverse effect induced in an organism in a short period (days) of exposure to a substance. In the present test, acute toxicity is expressed as the mean lethal concentration (LC50), which is that concentration of the test substance, o-chlorobenzylidene manolonitrile in water which causes the death of $50 \%$ of the batch of fish experienced during a period of exposure, continuous and defined.

The research activities that required work on experimental fish were carried out in accordance with the provisions of OM 143 of April 1, 2002 No. 400 of May 20, 2002 and ANSVSA Order No. 84 of August 30, 2005, GAP (Good Animal Practice) and GLP (Good Animal Practice).

The protocols according to which the fish research was carried out were drawn up in accordance with the rules of bioethics, and took into account the use of as few subjects as possible but sufficient in terms of scientific accuracy (biostatistically significant). The test for the determination of acute lethal toxicity of contaminants according to the SR 13216 standard is performed with freshwater fish species (eurytherms). The test is performed by the static method, when the concentrations of the impurities are kept relatively constant.

The study monitored the toxicity of o-chlorobenzylidene manolonitrile by exposing the fish to different concentrations of this substance, under conditions similar to a toxic aquatic concentration to which they could be exposed as a result of possible chemical contamination. The toxicity tests have the role of highlighting the physiological and/or anatomopathological changes induced by the administration/exposure to toxic substances. [(2-chlorophenyl) methylene] malononitrile is stable and incompatible with strong oxidizing agents. It is hydrolyzing in solution (half-life $15 \mathrm{~min}$ ) forming 2-chlorobenzaldehyde and malononitrile [19-21].

It should be noted that the results of the tests performed may be influenced by the exposure of fish to degradation products of [(2-chlorophenyl) methylene] malononitrile. Eurythemal fish studied in this experiment were followed during the experiment in terms of lethality, body weight, eating behavior, motor behavior, aggression, skin appearance. According to the SR 13216/1994 standard, two characteristics were taken into account - testing the body weight of the fish and their viability.

For the test to be valid, the fish studied had to meet certain living conditions for survival in the polluting environment - oxygen concentration, temperature, body weight and viability. Thus, the dissolved oxygen concentration had to be at least $60 \%$ of the air saturation value (VSA) throughout the test and the water temperature had to not differ by more than $\pm 10^{\circ} \mathrm{C}$ between the pools at any time 
during the test and was maintained in a range of $20^{\circ} \mathrm{C}$ within the temperature ranges specified for the fish species analyzed [12].

Fish are treated with the test substance solubilized in water, in a range of concentrations from 01$3.5 \mathrm{mg} / \mathrm{L}$, over a period of $72 \mathrm{~h}$. Mortality was recorded at $24 \mathrm{~h}$ intervals and the concentrations causing the death of $50 \%$ of the fish (LC50) were calculated. The test allowed to establish the interval and the limits of confidence, in order to obtain information related to the range of concentrations that the analyzed fish can withstand. In addition to the chemical test, a control test without CS substance is performed, the aquarium with the corresponding fish being called a control.

For each period in which observations were recorded $(24 \mathrm{~h}, 72 \mathrm{~h}$,) the mortality expressed as a percentage was plotted, depending on the concentration.

The classification according to Regulation (EC) No 1272/2008 according to the Safety Data Sheet ALDRICH-M1407 which complies with the requirements of EU Regulation No. 1907/2006 is as follows: Acute toxicity, Oral H301, Acute toxicity, Inhalation H331, Acute toxicity, Dermal, H311, Short - term (acute) danger to the aquatic environment (Category 1), H400. Long-term (chronic) danger to the aquatic environment (Category 1), H410 [13].

Information on toxicological effects - Acute toxicity - LD50 Oral - Mouse - $19 \mathrm{mg} / \mathrm{kg}$, Dermal LD50 - Rat - $350 \mathrm{mg} / \mathrm{kg}$. O-chlorobenzylidene manolonitrile can be partially metabolized to cyanide in the body, which are associated with headache, dizziness, convulsions, cyanosis, irregular breathing, lung irritation, central nervous system depression.

According to the Safety Data Sheet of 2-chlorobenzalmalononitrile, it has the toxicity to fish LC50 - Pimephales promelas $-0.51 \mathrm{mg} / 1-96.0 \mathrm{~h}$ and for daphnia and other aquatic invertebrates toxicity EC50 - Daphnia magna (water flea) - $21.4 \mathrm{mg} / \mathrm{L}$ - $24 \mathrm{~h}$ [14].

Rationale for the use of cyprinidae - BARBUS species Capoeta Tetrazone is a fish that belongs to the Cyprinidae family used in accordance with STANDARD SR 13214/1993 fish of the species CYPRINIDAE are used, according to the international STANDARD NEQ ISO 7346-1: 1984 for "Determination of acute lethal toxicity of substances in freshwater fish" (Static method ISO 7346-2 / 1984-Water quality-Determination of acute lethal toxicity of substances in freshwater fish-cyprinidaeSemistatic method and according to ISO 7346-3 / 1984 C WATER QUALITY Determination of acute total toxicity of substances in freshwater fish-Cyprinidae, Dynamic method Fish used in laboratory experiments were purchased through the store Nevertebrate.ro This species is native to Southeast Asia, Sumatra, Borneo, Thailand, and Malae. Zia. It lives in densely vegetated waters and feeds on Diatoms, algae, worms. It has dimensions in the range of $2.5-3 \mathrm{~cm}$. In the laboratory, during the adaptation period it was fed with granulated food distributed in daily rations consisting of green culture algae, distributed in equal portions with $1 \%$ of the weight of the fish.

\subsection{Preparation of test bodies}

The test organisms, sweet fish (eurythermal) Barbus Capoeta Tetrazona were procured from fish farms and came from the same fish group. Barbus Capoeta Tetrazone is a species in the Cyprinidae family, native to Southeast Asia, Sumatra, Borneo, Thailand, and Malaysia, living in dense vegetation and feeding on diatoms, algae, and small insects.

The optimum development temperature is $22-25^{\circ} \mathrm{C}, p \mathrm{H}: 6.5-7.5$, Hardness: $5-9^{\circ} \mathrm{H}$, Species dimensions: $5-3 \mathrm{~cm}$.

Eurythermal fish studied in this experiment were followed during the experiment in terms of lethality, body weight, eating behavior, motor behavior, aggression, skin appearance. These aspects were pursued in order to obtain scientific information aimed at supporting biological and medical research and were carried out in accordance with Government Ordinance no. 37/2002. In fish, tolerance to acidity, chlorine and other chemicals differs greatly from species to species. Therefore, attention was paid to the adaptation of the supply water in the aquarium and the experimental basins according to the needs and tolerance limits of eurytherms. Thus, the studied fish had a period of acclimatization before being used in experiments [15]. 
The laboratory where the fish were kept was arranged with a semistatic system, glass aquariums with dimensions of (5 cm diameter $* 70 \mathrm{~cm}$ length), capacity $1000 \mathrm{~mL}$, open. The essential conditions for the adaptation and maintenance of fish were to maintain the water temperature in the range of 20$25^{\circ} \mathrm{C}$, permanent aeration of water to maintain a dissolved oxygen content at $4 \mathrm{mg} / \mathrm{L}$, daily siphoning of organic waste and removal of dead fish or patients results during the experiment.

The dilution water used for the preparation of the test solutions, for the filling of the aquariums as well as for the control tests was the drinking water from the distribution network after its dechlorination. The results obtained from the laboratory analysis of the dilution water are presented in Table 1. The dilution water was added to the aquariums, aerated diffusely by bubbling air before adding fish to remove chlorine. After transport to the laboratory, the fish were accommodated for 2 weeks in the laboratory conditions (Figure 3).

Fish were examined daily during the test and any external abnormalities (such as bleeding, discoloration) and abnormal behavior were observed. The dead fish were removed from the aquariums as soon as possible. In the aquariums, no food was administered to eliminate the interference due to organic residues [17] and the laboratory lighting was maintained with a photojournalism of $12 \mathrm{~h} . . .16 \mathrm{~h}$ light daily. At the end of the test, all fish were weighed (Figure 4) blotted dry, in order to determine the individual specific growth rate, presented graphically in Figure 5, [18].

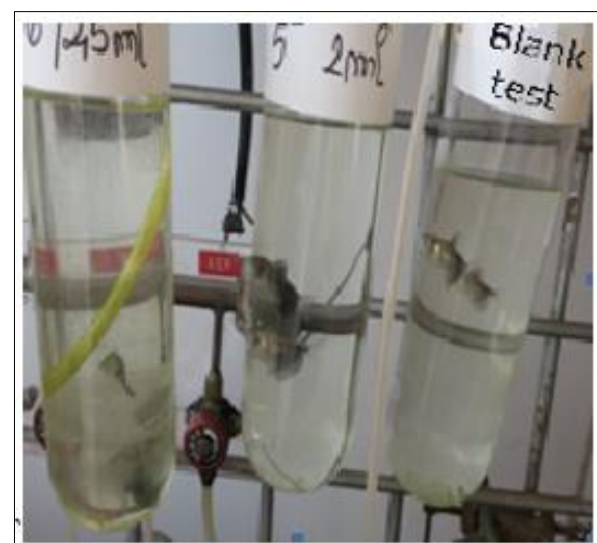

a)

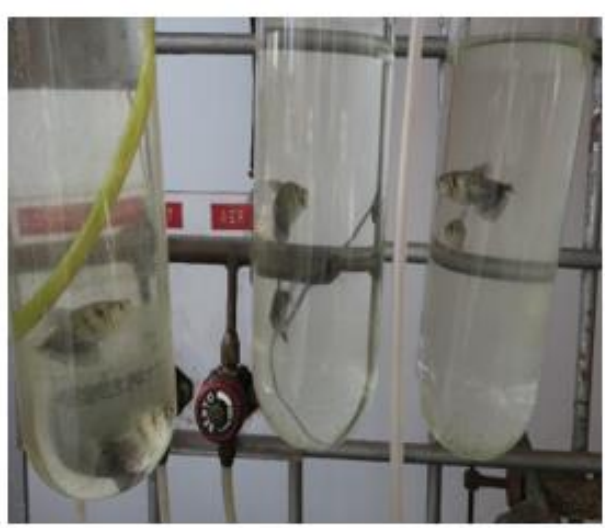

b)

\subsection{Devices}

Figure 3. Detail - fish initial stage

(a) $p \mathrm{H}$ meter

(b) oxygen meter;

(c) equipment for determining water hardness;

(d) water temperature control thermometer

(e) analytical balance

(f) oxygen meter

(g) aquarium compressor

(h) lie

(i) manolonitrile stock solution of concentration $100 \mathrm{ppm}$. The stock solution was prepared by ultrasonic stirring of manolonitrile in dilution water (bidistilled water).

Working solutions of concentrations from $0.1 \mathrm{mg} / \mathrm{L}$ to $3.5 \mathrm{mg} / \mathrm{L}$. The solutions were prepared by diluting the stock solution of manolonitrile in tap water.

\section{Results and discussions}

The chemical quality of the water in the fish aquariums is presented in Table 1 and respects the standardized prescriptions for the maintenance of eurythermal fish.

Table 1 shows the characteristics of the water used in the aquariums where the toxicity studies were performed. 
Table 1. The characteristics of water in aquariums without fish, after dechlorination by bubbling air

\begin{tabular}{|c|c|c|c|c|}
\hline $\begin{array}{c}\text { Dry filterable residue at } \\
105^{\circ} \mathrm{C}, \mathrm{mg} / \mathrm{L}\end{array}$ & Temperature, ${ }^{\circ} \mathrm{C}$ & $p \mathrm{H}$ & $\begin{array}{c}\text { Total hardness } \\
\mathrm{mg} / \mathrm{L}, \mathrm{CaCO}_{3}\end{array}$ & Oxygen, mg/L \\
\hline 350 & 23 & $7.2-8.5$ & 85 & 4 \\
\hline
\end{tabular}

During the tests, changes in motor behavior of the Barbus Capoeta Tetrazone fish (eg, loss of balance, swimming and respiratory disorders, changes in pigmentation, etc.) and manifestations of the aggressiveness of fish in polluted aquariums were observed. Following the evaluation of the physical aspects of the Barbus Capoeta Tetrazone fish analyzed, it was observed, through the evolution of body weight, the differences between the fish in the pools with different concentrations being a clinical sign of toxicity. The test was validated by the fact that the clinical signs were manifested by abnormal changes in body weight.

Laboratory tests were performed by the static method. The scope of the tests performed are useful because they allow the toxicological characterization of impurities and serve to determine the maximum permissible concentration of impurities tested for the protection of fish fauna. In future tests we aim to test wastewater contaminated with industrial or urban effluents and in this case the test result will give information that allows toxicological characterization in order to analyze the efficiency of treatment in pilot stations [19-21]. Thus, the allowed dilution ratio can be estimated, so as not to destroy the treatment efficiency applied in the technological installations.

Frequency of renewal of solutions.

In the tests performed, the aim was to highlight the concentrations in which mortality was close to $100 \%$ and concentrations in which the mortality was below 50\%. In the analyzed tests, the static method was chosen in the preliminary test. final concentrations remained constant. Because in the preliminary test there were deaths close to $100 \%$, we opted for the same concentrations in the final test.

In the tests performed according to SR 13216/1994, the body weight of Barbus Capoeta Tetrazone fish and their viability were taken into account. The body appearance of the analyzed fish from different aquariums showed that they had a different growth, depending on the concentration of manolonitrile in which it was exposed (Figure 4).

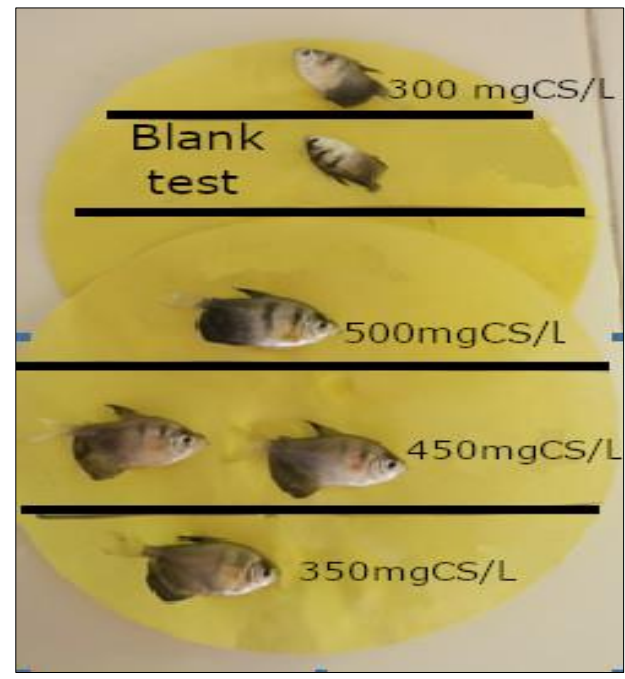

Figure 4. Body weight variation

Following the analyzes performed, it was found that the weight of the fish increased differently until the end of the test, which allowed the detection of the minimal variation of the growth rate. This evolution is presented graphically in Figure 5. 


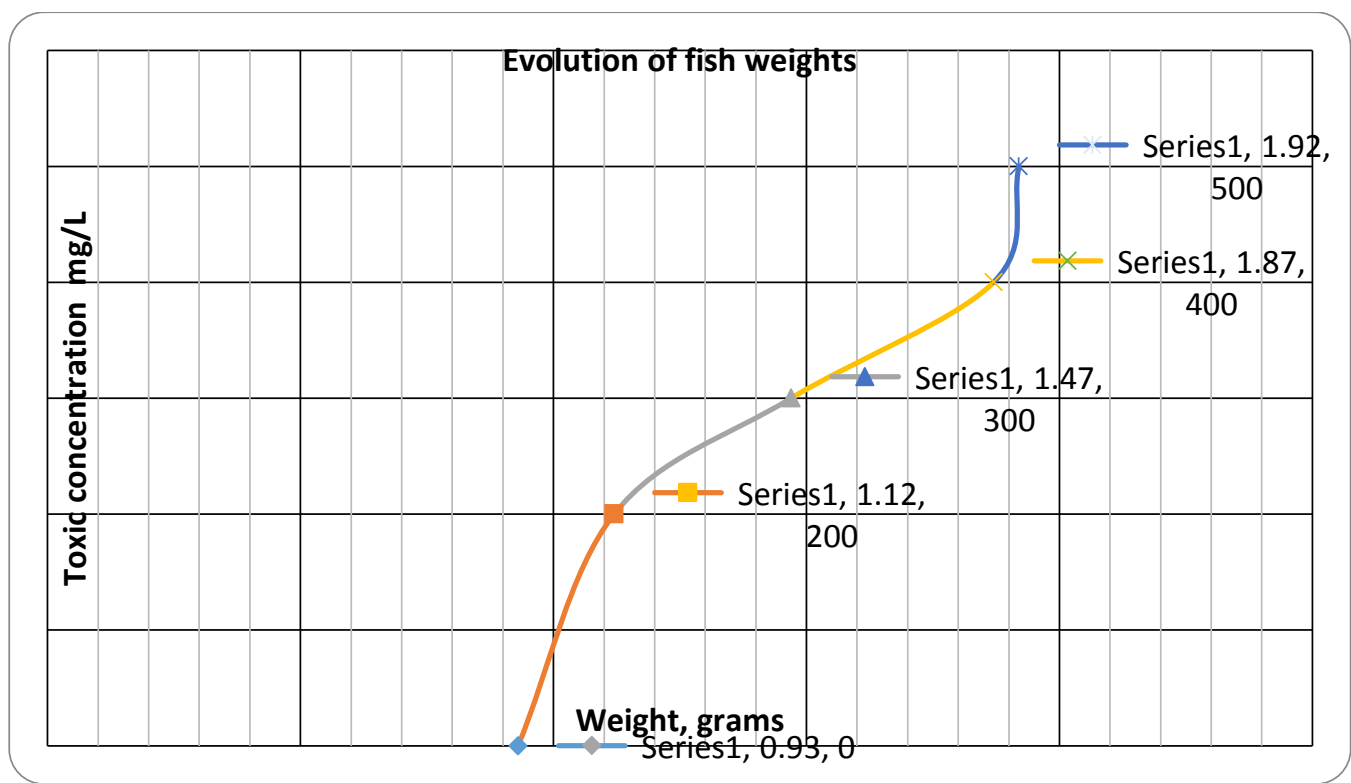

Figure 5. Graph of body weight variation

In the Table 2 are shown the probit values corresponding to the mortality percentages $0 \% \ldots 100 \%$, corresponding to the concentrations tested in periods of $24 \mathrm{~h} . .72 \mathrm{~h}$. To determine the probit values, it was considered that the death of the fish occurred when the respiratory movements stopped and the fish fell in lateral or dorsal decubitus did not react to arousals, such as touching with the top of the glass rod.

Table 2. Probit values corresponding to mortality rates

\begin{tabular}{|c|c|c|c|c|c|c|c|c|c|}
\hline \multirow{2}{*}{$\begin{array}{l}\text { Stock solution } \\
\text { added to } \\
\text { aquariums, } \\
\mathrm{mL}\end{array}$} & \multirow{2}{*}{$\begin{array}{c}\text { The amount } \\
\text { of toxic added } \\
\text { to aquariums, } \\
\mu \mathrm{g}\end{array}$} & \multirow{2}{*}{$\begin{array}{c}\text { Concentration, } \\
\mathrm{mg} / \mathrm{L}\end{array}$} & \multirow{2}{*}{ Aquarium } & \multicolumn{2}{|c|}{ Death rate \% } & \multirow{2}{*}{$\begin{array}{c}\text { Test, } \\
\mathrm{h}\end{array}$} & \multirow{2}{*}{$\begin{array}{c}\text { Probit units } \\
\text { (according to } \\
\text { SR13216 Annex B) }\end{array}$} & \multirow{2}{*}{$\begin{array}{c}\text { Test, } \\
\mathrm{h}\end{array}$} & \multirow{2}{*}{$\begin{array}{l}\text { Probit units } \\
\text { corresponding } \\
\text { to mortality } \\
\text { rates (according } \\
\text { to SR13216 } \\
\text { Annex B) }\end{array}$} \\
\hline & & & & $24 \mathrm{~h}$ & $72 \mathrm{~h}$ & & & & \\
\hline 0 & 0 & 0 & 1 blank test & 0 & 0 & 24 & 0 & 48 & 0 \\
\hline 0.5 & 50 & 0.1 & 2 & 0 & 0 & 24 & 0 & 48 & 0 \\
\hline 1 & 100 & 0.2 & 3 & 0 & 0 & 24 & 0 & 48 & 0 \\
\hline 1.5 & 150 & 0.3 & 4 & 0 & 0 & 24 & 0 & 48 & 0 \\
\hline 2 & 200 & 0.4 & 5 & 0 & 0 & 24 & 0 & 48 & 0 \\
\hline 2.5 & 250 & 0.5 & 6 & 0 & 0 & 24 & 0 & 48 & 0 \\
\hline 0 & 0 & 0 & 1 blank test & 0 & 0 & 24 & 0 & 48 & 0 \\
\hline 3 & 350 & 0.7 & 2 & 0 & & 24 & 0 & 48 & 0 \\
\hline 3.5 & 450 & 0.9 & 3 & 0 & 50 & 24 & 0 & 48 & 5 \\
\hline 4 & 550 & 1.1 & 4 & 0 & 50 & 24 & 0 & 48 & 5 \\
\hline 4.5 & 650 & 1.3 & 5 & 0 & 50 & 24 & 0 & 48 & 5 \\
\hline 5 & 750 & 1.5 & 6 & 0 & 50 & 24 & 0 & 48 & 5 \\
\hline 0 & 0 & 0 & 1 blank test & 0 & 0 & 24 & 0 & 48 & 0 \\
\hline 6 & 950 & 1.9 & 2 & 0 & 100 & 24 & 0 & 48 & 8.7 \\
\hline 7 & 1150 & 2.3 & 3 & 50 & 100 & 24 & 5 & 48 & 8.7 \\
\hline 8 & 1350 & 2.7 & 4 & 50 & 100 & 24 & 5 & 48 & 8.7 \\
\hline 9 & 1550 & 3.1 & 5 & 50 & 100 & 24 & 5 & 48 & 8.7 \\
\hline 10 & 1750 & 3.5 & 6 & 100 & 100 & 24 & 8,7 & 48 & 8.7 \\
\hline
\end{tabular}

Table 3 - Recording of lethal responses, according to SR13216, shows the information in which the logarithms of the tested concentrations are calculated in order to be able to estimate the $95 \%$ confidence interval. Those values corresponding to the tests in which the mortality was $50 \%$ were chosen. 
Table 3. Registration of lethal responses according to SR13216

\begin{tabular}{|c|c|c|c|c|}
\hline Concentration, mg/L & $24 \mathrm{~h}$ & $72 \mathrm{~h}$ & $\begin{array}{c}\text { Log (concentration x10, } \\
\text { mg/L pollutant) } \\
24 \mathrm{~h}\end{array}$ & $\begin{array}{c}\text { Log (concentration x10, } \\
\text { mg/L pollutant) } \\
72 \mathrm{~h}\end{array}$ \\
\hline 0.1 & 0 & 0 & - & - \\
\hline 0.2 & 0 & 0 & - & - \\
\hline 0.3 & 0 & 0 & - & - \\
\hline 0.4 & 0 & 0 & - & - \\
\hline 0.5 & 0 & 0 & - & - \\
\hline 0.7 & 0 & 0 & - & 1.04 \\
\hline 0.9 & 0 & 1 & - & 1.11 \\
\hline 1.1 & 0 & 1 & - & 1.17 \\
\hline 1.3 & 0 & 1 & - & - \\
\hline 1.5 & 0 & 1 & - & - \\
\hline 1.9 & 0 & 2 & - & - \\
\hline 2.3 & 1 & 2 & 1.36 & - \\
\hline 2.7 & 1 & 2 & 1.43 & - \\
\hline 3.1 & 1 & 2 & 1.49 & \\
\hline 3.5 & 1 & 2 & 1.54 & \\
\hline
\end{tabular}

The estimation of the LC50 value was performed by the probit analysis method, by plotting. Thus, the mortality percentages expressed in probit units were written on the ordinate and the logarithm of the concentrations corresponding to the test period of $24 \mathrm{~h}$ and $72 \mathrm{~h}$, respectively, on the abscissa of (Figure 6). 95\% confidence was made by the WEBER method [16].

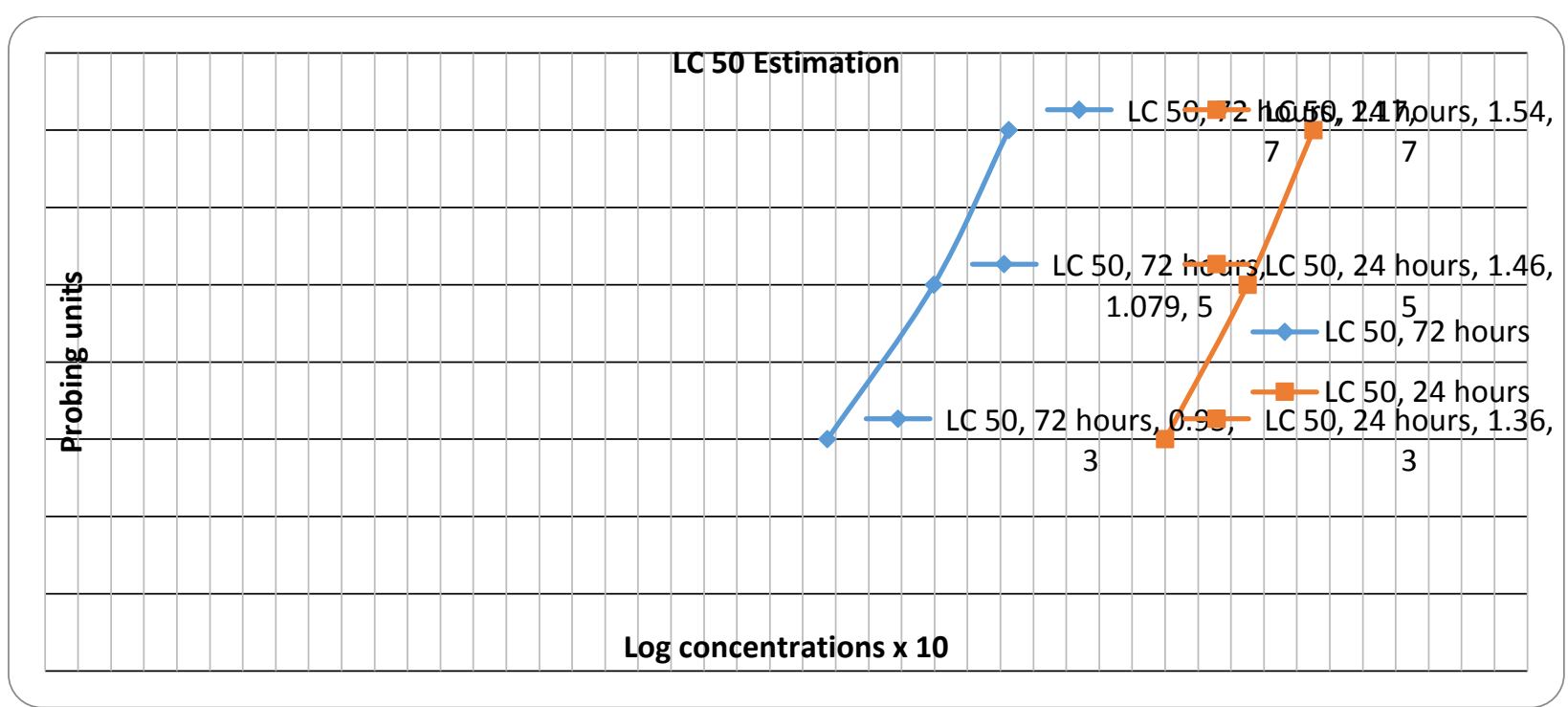

Figure 6. Estimation of mean lethal concentration (LC 50)

\section{Conclusions}

The toxic effects of o-chlorobenzylidene manolonitrile on Barbus Capoeta Tetrazone fish were manifested by the changes in the visible abnormal motor behavior and manifestations of aggression of the fish from the polluted aquariums. These aspects are clinical signs due to the toxicity of ochlorobenzylidene manolonitrile [19].

The toxic effects of o-chlorobenzylidene manolonitrile on Barbus Capoeta Tetrazone fish were also manifested by the evolution of body weight, the differences between the weight of fish in pools with different concentrations being a clinical sign of toxicity. The obtained results confirm the tendency of increasing the body weight of the fish with the time of standing in the toxic environment. In this way, the validity criteria of the tests performed were established, thus being able to identify the intervals estimated by LC50. LC50 estimated at $24 \mathrm{~h}$ with $95 \%$ confidence interval is 1.46 for an average concentration of o-chlorobenzylidene manolonitrile of $2.9 \mathrm{mg} / \mathrm{L}$, and LC50 estimated at $72 \mathrm{~h}$ with $95 \%$ 
confidence interval is 1,079 for a mean concentration of o-chlorobenzylidene manolonitrile of $1.2 \mathrm{mg}$ /L. Studies performed on fish species from Fam. Cyprinidae, through ecotoxicological tests, have allowed the study of behavioral parameters in the applied chemical stress. Based on the results of LC50 $24 \mathrm{~h}$ and LC50 72h, the maximum average lethal concentration of the pollutant such as CS gas (ochlorobenzylidene manolonitrile) in surface waters could be estimated so that the natural ecosystem is protected.

\section{References}

1.CORSON, B.B, STOUGHTON, R.W, Reactions of Alpha, Beta-Unsaturated Dinitriles, Journal of the American Chemical Society, 50 (10), 1998, 2825-2837

2.***https://www.opcw.org/our-work/what-chemical-weapon

3.KARAGAMA, Y.G, NEWTON, J.R, NEWBEGIN, C.J, Short-term and long-term physical effects of exposure to CS spray, JRSM, 96(4), April 2003, 172-174

4.HOWARD, HU, Tear Gas - Harassing Agent or Toxic Chemical Weapon?, The Journal of the American Medical Association, 262 (5), (4 August 1989, 660-663

5.***Jandarmeria: Gazele lacrimogene folosite la proteste provin exclusiv de la producători autorizaţi şi certificaţi. Substanţele sunt folosite şi de forţe de ordine europene". Mediafax, Bucharest, 15 August 2018 6.LEUNG, K., CHEONG, K., "Why police should limit the use of tear gas, EJ Insight, 20 August 20197.RAMZY, A, LAI, K.R., 1,800 Rounds of Tear Gas: Was the Hong Kong Police Response Appropriate? The New York Times, 18 August 2019

8. ZUCCHETTI, M., TESTONI, R., Fresenius Environmental Bulletin, 26 (1), 2017, 151-155

9. IAN FRESHNEY, R., Culture of Animal Cells: a manual of basic technique, Fourth Edition ISBN: 0-471-34889, 2005

10. ***REACH, Regulamentul Comisiei Nr. 440/2008

11. ***Jurnalul Ofícial al Uniunii Europene L 383/113 vol. 12 31992L0069/1992 partea C-cap. C1 Toxicitatea acută la pești

12.***STANDARD SR 13216/1994, Ape de suprafata si ape uzate. Teste cu organisme acvatice. Determinarea toxicitatii letale acute a impurificatorilor si apelor uzate fata de pesti dulcicoli (euritermi)

13. ***https://www.ilo.org/safework/info/publications/WCMS_113134/lang--en/index.htm\%20

14. ***Fisa tehnica de securitate ALDRICH- M1407

15. ***http://www.monitoruljuridic.ro/act/ordin-nr-143/2002

16. STEPHAN, C. E., Methods for calculating an LC50. In Aquatic Toxicology and Hazard Evaluation, American Society for Testing and Materials, ASTM STP 634, 1977, 65-84

17. GHEORGHE, V., GHEORGHE, C.G., BONDAREV, A., MATEI, V., BOMBOS, M., Rev. Chim., 70(8), 2019, 2996-2999

18. NICOLESCU, F., LUPU, F., PANTEA, O., GHEORGHE, C.G., BONDAREV, A., CALIN, C., Rev. Chim., 66(8), 2015, 1181

19. ASHLEY, S., MALLETT, M. J., GRANDY, N. J. EEC Ring Test of a Method for Determining the Effects of Chemicals on the Growth Rate of Fish. Final Report to the Commission of the European Communities, 1990

20. ***WRC Report No EEC 2600-M., 2000

21. ***Https://echa.europa.eu/ro/registration-dossier/-/registred-dossier/26045/9

Manuscript received : 15.05 .2020 